\title{
Entrepreneurial Orientation, Distinctive Marketing Competencies and Organizational Performance
}

Dr. Denise T. Smart, Marketing, University of Nebraska at Omaha Dr. Jeffrey S. Conant, Marketing, Texas A\&M University

\begin{abstract}
This study examined the entrepreneurial orientation (EO) of 599 independent businesspeople and compared those with high, medium and low EO along a series of distinctive marketing competency and organizational performance measures. EO is measured using a new multi-item scale that is based on an integrative definition of entrepreneurship. Results indicate that EO is positively and significantly related to distinctive marketing competencies and organizational performance. Demographic profiles of the high, medium and low EO groups are also developed and provide additional insights.
\end{abstract}

\section{Introduction}

As important as any other factor, America is in a mood to cheer for entrepreneurs. The U.S. has raised them to the status of heroes and made entrepreneurship a national mission.... Entrepreneurship fits what many see as the new economy emerging in the 1990s (Main, 1990, pp. 120-121).

As encouraging as that observation might be, how to define, study and develop entrepreneurs remains elusive and challenging. Although there is evidence that the concept of an entrepreneur has been evolving since some time in the $1500 \mathrm{~s}$, what is collectively known about entrepreneurship today is still relatively limited (Cunningham and Lischeron, 1991). A variety of approaches for studying entrepreneurs and entrepreneurial behavior have been explored including looking at the social and economic context in which entrepreneurial ventures develop to analyzing the individual traits of entrepreneurs. Unfortunately, most of the research to date has suffered from the lack of a common definition of entrepreneurship, relied on small samples and employed unsophisticated analytical methods (Churchill and Lewis, 1986; Cooper and Dunkelberg, 1986; Kuratko and Hodgetts, 1992; Low and Macmillan, 1988). In addition, the types of strategy-performance linkages that have helped elevate the status of the strategic management field have been slow to develop in the entrepreneurship literature, primarily because many entrepreneurial studies have failed to include organizational performance measures in their research designs (Van de Ven, Hudson, and Schroeder, 1984). This latter limitation may be related in part to the fact that much of the research on entrepreneurs completed in the last 40 years has been conducted by researchers in non-business disciplines (Wortman, 1987).

Building on these research challenges, the purpose of this article is to report the results of a study that empirically examines entrepreneurial orientation and its relationship to distinctive marketing competencies and organizational performance. The basis for the categorization of respondents is a multi-item entrepreneurial orientation (EO) scale based on a proposed definition of entrepreneurship. To structure the discussion, the entrepreneurship literature is briefly reviewed first and a synthesized definition of entrepreneurship proposed. Next, the methodology used in the study is described, followed by presentation and discussion of the results, and directions for future research.

\section{Entrepreneurship: An Overview of the Literature}

In looking for consistent patterns in entrepreneurship research, Cunningham and Lischeron (1991) found that four main areas emerged. These included the study of personal characteristics, the recognition of opportunities, management and leadership styles, and the adaptation of an existing venture or intrapreneurship. Accompanying each of these areas is a set of specific beliefs about the nature of entrepreneurship. These beliefs range from early thinking that entrepreneurs were "great men" 
with innate abilities to viewing the entrepreneurial process as one of organization and leadership. Other consistencies, noted by Long (1983), were three main themes found in formal theories of entrepreneurship including: (1) uncertainty and risk stemming from a variety of obstacles and self-employment; (2) the ability to perform managerial tasks competently; and, (3) creative opportunism consisting of identifying and exploiting ideas. In broad terms, work in the area can be generally viewed as either trait-related or behaviorrelated.

A sizable amount of previous research has focused on specific traits of entrepreneurial individuals. Myriad variables have been considered ranging from McClelland's (1965) need for achievement to internal locus of control and tolerance for ambiguity (Begley and Boyd, 1987). While there is some support for selective traits, it is limited. Cooper and Dunkelberg (1987) looked at 890 entrepreneurs and found several traits related to entrepreneurship. These included having a somewhat better education, coming from families where the parents owned a business, working in areas related to what they had done before and locating the venture where they were already living. While these similarities are noteworthy, a general conclusion from the research was that, "Diversity seems to be a central characteristic of entrepreneurial activity and of the new firms which are then established" (Cooper and Dunkelberg, 1987, p. 21). Some concur that entrepreneurs are at best difficult, and quite likely, impossible to profile (Gartner, 1985; Low and MacMillan, 1988), while others (Carland, Hoy, and Carland, 1988) maintain that personality traits remain an important avenue for future study.

Given the limited success and methodological difficulties inherent in pursuing the trait approach, a behavior or process-oriented approach, has received increased attention in recent years. This approach looks at the entrepreneurial process in terms of the entrepreneur's activities rather than specific individual traits. As Gartner (1988) argues, the focus should be on what the entrepreneur does rather than on who the entrepreneur is. Further, he concludes that the entrepreneur is not, "a fixed state of existence, rather...a role that individuals undertake to create organizations" (p. 28).

In creating those organizations, what the entrepreneur does consists of a variety of activities including identifying opportunities, securing resources, marketing products and services, producing products, building organizations and responding to government and society (Gartner, 1985). Key dimensions in the process are thought to be innovation, risk-taking and proactiveness which implies an active management style where the entrepreneur works directly not only with customers but also with intermediary channel members (Covin and Slevin, 1989). The process approach also implies that entrepreneurship occurs to some degree in all societies and all organizations (Davis, Morris, and Allen, 1991).

An integral part of the entrepreneurial process revolves around the concept of strategic choice and, although few empirical studies have focused on entrepreneurship strategy (Low and MacMillan, 1988), there is a growing recognition of its relevance in the successful entrepreneurial process (Carland, et al., 1984). As Bird (1989) concludes in a comprehensive review of entrepreneurial behavior:

At the earliest stages, most entrepreneurs will tend to be more or less creative, visionary, opportunistic, intentional, and controlling. As their enterprises begin to take on lives of their own, intentional action competencies (e.g., sustaining temporal tension, strategic focus, choosing ends and/or means, and alignment of self and others into internal and external teams) will take on increasing importance ( $p$. 374).

Although a single definition of entrepreneurship does not exist (Kuratko and Hodgetts, 1992) and a commonly accepted definition likely will go unfulfilled into the future (Low and MacMillan, 1988), for the purposes of this study a guiding definition of entrepreneurship is proposed. Based on the most comprehensive overviews of literature in the area (Cunningham and Lischeron, 1991; Long, 1983; Miles and Arnold, 1991), the following definition is proposed:

Entrepreneurship is a dynamic goal-oriented process whereby an individual combines creative thinking to identify marketplace needs and new opportunities with the ability to manage, secure resources and adapt to the environment to achieve desired results while assuming some portion of risk for the venture.

While this definition certainly is not inclusive of all views on the subject, it recognizes the possibility that entrepreneurship may contain both individual traits and behavior-related skills. Given that entrepreneurs are thought to possess certain venture building skills, it follows that there may be marketing competence and organizational performance differences among businesspeople with varying entrepreneurial orientation levels.

\section{Marketing and Entrepreneurship}

As suggested by Davis, Morris, and Allen (1991), the natural bond between marketing and entrepreneurship may be value creation. Although Schumpeter (1934) first brought attention to the value creation function of entrepreneurs, others (Carland, et al., 1984; Vesper, 1980) have also recognized the role of value creation. Schumpeter (1934) suggested five categories of behavior that identified an entrepreneurial venture. They included: (1) introduction of new goods; (2) introduction of 
new methods of production; (3) opening of new markets; (4) opening of new sources of supply; and, (5) industrial reorganization. Bird (1989) suggests adding a sixth to the list: the introduction of new services. Notably, characteristics $1,3,4$ and 6 are distinctly marketing-related.

Others have recognized the need for marketing expertise in the entrepreneurial process. For example, Nicholson (1986) posits that one of the ten critical factors for success of an emerging business is marketing, sales and service effectiveness. Low and Macmillan (1988) recommend giving consideration to if there is an established, defensible market for the product and whether a market niche can be secured. They also recognize that entrepreneurs must exploit certain opportunities requiring a variety of competencies some of which are human resources, capital, marketing and technical information, and sales. Wortman (1987) suggests an appropriate question for future research is whether successful entrepreneurial ventures are related to one or more managerial functions such as marketing.

While there is a growing recognition of the need for entrepreneurs to possess marketing competencies, much of the research to date has been done within a general management context with marketing-related variables receiving only indirect attention. Just recently the relationship between marketing orientation and entrepreneurial orientation has attracted the interest of researchers. Morris and Paul (1987) studied 116 companies in central Florida and found that companies that scored higher on entrepreneurial orientation measures also tended to be more marketing oriented. These companies were more likely to have a formal marketing department, to do marketing research on a regular basis, to have marketing personnel in senior executive positions and to acknowledge the importance marketing played in innovation and strategy development for the firm. Another study based on 169 responses from top managers of furniture manufacturing firms also found a significant correlation between entrepreneurial orientation and marketing orientation (Miles and Arnold, 1991). Further analysis suggested that the two orientations were separate constructs and did not describe the same underlying business philosophy. Environmental dynamics was seen as a key factor in explaining differing responses.

Another study examined 14 educational software company startups, each with some support from a large computer-manufacturing firm (Van de Ven, Hudson, and Schroeder, 1984). Several planning variables were studied from an organizational management perspective and it was found that more successful entrepreneurs had a greater external orientation evidenced by the degree of search in assessing the firm's market niche and competition, and the amount of involvement of potential customers and professional consultants in developing the business plan.

Even though research studying the entrepreneurship and marketing interface is in its earliest stages (Hills and LaForge, 1992), there is emerging support for the view that entrepreneurs possess marketing competencies. The study that follows focuses on independent businesspeople and examines the relationship between distinctive marketing competencies and entrepreneurialorientation. Specifically, the first research question is:

Do businesspeople with higher degrees of entrepreneurial orientation also report more marketing competencies?

\section{Organizational Performance and Entrepreneurship}

Although figures vary, Small Business Administration data indicate that up to $60 \%$ of new small businesses fail in the first six years (Main, 1990). Concerns over cash flow and the greater probability of being undercapitalized are important issues for the small retailer (Fiorito and LaForge, 1986). With such high failure potential some may argue that the ultimate measure of entrepreneurial success is simply survival.

The survival criterion as an indicator of a small firm's organizational performance has been used in most empirical studies that examine the relationship between strategic management practices and organizational performance. This measure does provide some sense of performance, albeit a limited perspective. Its popularity stems from several sources. One is the sensitivity that small firm businesspeople tend to have about releasing performance-related data. Others are the lack of publicly available information and the risks associated with using trade-supplied aggregate data that may be based on very different accounting systems (Dess and Robinson, 1984). The need to go beyond mere survival in assessing small firm performance is increasingly recognized.

Most of the limited amount of literature related to small firm performance focuses on its relationship to planning practices (Keats and Bracker, 1988). There is increasing interest in planning's positive relationship to a small firm's continued success. In a review of $\mathbf{5 0}$ planning-related studies based on small firm samples, Robinson and Pearce (1984) concluded that most of the studies that examined the value of strategic planning found its presence or lack thereof influenced the ultimate viability of the firm. Specifically, four studies looked at planning and firm success over time. Each provided some support for a positive link among growth, profit and strategic planning variables.

Covin and Slevin (1989) examined 161 independentlyowned, small, primarily manufacturing-related business- 
es. They found that environmental hostility was related to entrepreneurial strategic posture and performance. Entrepreneurial strategic posture contributed to high performance among small firms facing a hostile business environment while a more conservative approach benefitted firms in a benign environment. Recognizing the complexity of the situation they concluded that, "Performance is, presumably, a function not only of a firm's organization structure and strategic posture, but also of the fit between these variables and the firm's business practices and competitive tactics (p. 84)."

In a study of 81 independent grocery stores, it was found that operational planning was associated with higher performance (Robinson, Logan, and Salem, 1986). Operational planning describes more tactical, short-term, less comprehensive planning activity which is completed at a lower level and involves smaller amounts of resources. This type of planning might be more closely associated with entrepreneurial ventures, especially those that are relatively new.

As noted by Morris and Paul (1987), "...the nature of the interrelationship between marketing and entrepreneurship has not been related to a company's bottom line" (p. 258). Even though direct empirical evidence supporting the link among planning, entrepreneurship and company performance is not yet apparent, planning is recognized as an important tool for dealing with economic instabilities and for maintaining the ability to take advantage of new market opportunities (Jones, 1982; Meziou, 1991). A key dimension of entrepreneurship is the ability to identify and recognize new opportunities. Another factor more recently associated with entrepreneurship is strategic choice. The planning literature supports the link between planning practices and business success. Given that entrepreneurs are thought to have the ability to scan the environment and discover new opportunities while being innovative, taking risks and planning for the future, planning may provide the indirect avenue for linking entrepreneurial orientation and company performance. This suggests the following research question:

Do businesspeople with higher degrees of entrepreneurial orientation also report more favorable organizational performance?

\section{Methodology}

A cross-sectional field study of 1459 independentlyowned apparel specialty retailers was undertaken following the development and pretesting of a survey instrument. Apparel specialty retailers were selected because apparel retailing is an important aspect of the overall retail category and provides homogeneity for analysis purposes (Fiorito and LaForge, 1986). Independent retailers were selected to distinguish them from intrapreneurs or those individuals working within established organizations. Also, these firms could be categorized as small businesses and small business may be the most appropriate context within which to study entrepreneurial activity because of the risks involved in owning a small firm (Kalleberg, 1986).

The list of retailers was provided by an apparelrelated organization that has on-going contact with each of these firms. Firms were located throughout the United States with a majority situated in the southcentral and southeast.

A three-wave mailing was employed using many of the response facilitation techniques recommended by Dillman (1978). The first wave consisted of a questionnaire and cover letter explaining the purpose of the study, promising the respondent anonymity and offering a summary of results for return of a completed questionnaire. A postage-paid return envelope was included in the mailing. Letters were addressed to the owner or manager of the business based on the assumption that entrepreneurs have the responsibility for the venture or, at least, share some of the risks and attendant rewards associated with it (Cunningham and Lischeron, 1991). A follow-up postcard reminder and thank you was mailed one week after the initial questionnaire. The third mailing, sent out two weeks after the postcard reminder, included a slightly modified cover letter (one that more strongly encouraged respondent participation), another copy of the questionnaire and a postagepaid return envelope. This third mailing was only sent to those independent retailers who had not responded as of the follow-up mailing date.

\section{Measures}

\section{Entrepreneurial Orientation}

In this study entrepreneurial orientation (EO) was operationalized and measured using a six-item scale. The EO scale was designed after reviewing prior research on the definition of entrepreneurship. For example, and as previously discussed, Long (1983) identified three recurring themes in entrepreneurship definitions including uncertainty and risk, complementary managerial competence and creative opportunism. Carland, Hoy, Boulton, and Carland (1984) suggest that entrepreneurs are characterized by innovative behavior and the application of strategic management principles.

Building on these articles, other definitions of entrepreneurship and the definition proposed earlier, the six items included in the EO scale developed for this study were: (1) propensity to take risks; (2) tendency to engage in strategic planning activities; (3) ability to identify customer needs and wants; (4) level of innovation; (5) ability to persevere in making your vision of the 
business a reality; and (6) ability to identify new opportunities. The scale required respondents to evaluate these items relative to retailers who manage stores of similar sales volume in their area. Recognizing the positive relationship found to exist between the number of scale points and reliability in a meta-analytic study by Churchill and Peter (1984), a seven-point scale with values ranging from "1=Much Lower" to "7=Much Higher" was utilized.

\section{Distinctive Marketing Competencies}

Marketing competencies were measured using a modified and expanded version of the 20 -item Distinctive Marketing Competencies scale developed by Conant, Mokwa, and Varadarajan (1990). Developed after an extensive literature review that concentrated on the activities marketing managers perform, that scale, like other, more broad-based distinctive competency scales (e.g., those developed by Hitt and Ireland, 1985; Snow and Hrebiniak, 1980), reflects a dual focus. Some of the scale items relate to activities that facilitate the implementation of strategies (e.g., planning process activities), while others relate to realized marketing effectiveness (e.g., capabilities in specific marketing activities such as pricing).

In this study, the wording used by Conant, Mokwa, and Varadarajan on select items was refined to reflect the retailing context (their study surveyed health maintenance organization marketing directors) and several new items were added bringing the total number to 25. These new items were identified following a review of current retailing texts that delineate the marketing activities retailers perform (e.g., Berman and Evans, 1989; Mason and Mayer, 1987). Survey respondents were asked to evaluate their marketing competencies on 7-point scales that ranged from "Much Better/Much Higher" to "Much Worse/Much Lower." All 25 distinctive marketing competencies are contained in Table 1.

\section{Organizational Performance}

Organizational performance was measured using a subjective, self-report instrument comprised of seven items. These items receive frequent attention in retailing evaluation and control systems and include: (1) sales per square foot; (2) cash flow management; (3) effectiveness of cost containment; (4) sales per employee; (5) net income after taxes; (6) total sales growth over past 3 years; and (7) overall store performance/success.

These seven organizational performance dimensions were purposely embedded within the distinctive marketing competency section of the survey and were similarly assessed on 7-point scales that ranged from "Much Better" to "Much Worse." Organizational performance evaluations, like those for distinctive marketing compe- tencies, are more meaningful when assessed comparatively. In addition, the pretest indicated that respondents carefully evaluated each of the seven performance items when they were randomly dispersed within the distinctive marketing competencies. As previous research on the measurement of business economic performance has indicated, managerial assessments are generally consistent with objective performance measures internal to the organization (Dess and Robinson 1984), as well as secondary published performance information external to the organization (Venkatraman and Ramanujam, 1987).

\section{Validity Checks}

The content validity of the survey was assessed in a pretest with five independent apparel retailers not included in the sampling frame. Pretest participants were asked to evaluate all aspects of the questionnaire, including the wording of individual items, the general flow and structure of the instrument and its comprehensiveness. Participants' suggestions were then incorporated into the survey prior to its mailing.

\section{Results}

\section{Response Rate Summary and Nonresponse Bias Checks}

The three-wave mailing, which employed many of the response facilitation techniques recommended by Dillman (1978), resulted in the return of 601 surveys, 599 of which were usable for the analysis presented. This is a response rate of 41 percent.

Slightly more than one-half $(55.5 \%)$ of the respondents were female. Almost one-half of the respondents held college degrees $(46.4 \%)$, another $8.4 \%$ indicated they had some graduate school experience, $32.8 \%$ had attended but not graduated from college and $12.4 \%$ were high school graduates. Respondents' ages approximated a normal distribution with $4.6 \%$ less than or equal to $29,40.9 \% 30-45$ years old, $39.9 \%$ 46-60 years old and 14.6\% 61 and over. Four out of five respondents $(80.9 \%)$ described themselves as store owners, $8.0 \%$ store managers, $6.2 \%$ store presidents and $4.9 \%$ miscellaneous other titles. Respondents also indicated that on average their business included 1.5 store locations, each with approximately 3900 square feet and 11 employees.

To test for nonresponse bias, a telephone survey was conducted with 50 nonrespondents selected at random from the original mailing list. Five descriptive questions that had been included in the final section of the mail survey were asked of the nonrespondents (e.g., average store size, number of store locations). A series of independent t-tests comparing respondents and nonrespondents showed no significant differences. These 
findings suggest that nonresponse bias is negligible and that the results may generally be extended to the independent retailers who did not respond.

\section{Construction of the Entrepreneurial Orientation (EO) Scale}

Prior to examining the relationship between EO and distinctive marketing competence, as well as that between EO and organizational performance, the strength of the EO scale was assessed by examining its reliability. Benchmarks in this regard have been established by Covin and Slevin (1989), whose nine-item scale produced a coefficient alpha of .87 , and by Miles and Arnold (1991), who used the Covin and Slevin scale and found it produced a coefficient alpha of .83. An eightitem scale developed by Davis, Morris, and Allen (1991) produced an alpha of .63 while a 13 -item scale by Morris and Paul (1987) resulted in a .79 alpha. The sixitem EO scale used in the present study produced a coefficient alpha of .84. Given the more parsimonious nature of this new scale, it is very encouraging that its reliability approximates those produced by other EOrelated scales and exceeds Nunnally's (1978) .70 baseline for scales that are in their developmental stages.

For analysis purposes, respondents were divided into three approximately equal groups. Those scoring from 35 to 42 on the six 7-point EO scale items were placed in the high EO group ( $n=197)$, those scoring from $30-34$ in the medium EO group $(n=222)$ and those scoring 29 or below in the low EO group $(n=180)$.

\section{Entrepreneurial Orientation and Distinctive Marketing Competencies}

The overall nature of the relationship between EO and distinctive marketing competence was first examined using a multivariate analysis of variance (MANOVA). This relationship was found to be statistically significant (Wilks' criterion MANOVA F=9.09; $\mathrm{p} \leq .001$ ). Closer examination of the relationship between the 25 distinctive marketing competencies and $\mathrm{EO}$ was warranted by the significant MANOVA and was conducted using a series of ANOVAs. The exact nature of the differences among EO groups was identified by computing TukeyKramer pairwise comparisons (utilized because of the uneven EO group sizes) for all possible two-group combinations. Results of the univariate ANOVAs and pairwise comparisons are presented in Table 1.

As the findings in Table 1 indicate, a very strong relationship appears to exist between $\mathrm{EO}$ and distinctive marketing competence. In fact, on all 25 items the mean for the high EO group was significantly greater than the means for the medium and low EO groups. In addition, the means for the medium EO group are significantly greater than the means for the low EO group on all but two distinctive marketing competencies (knowledge of competitors and civic involvement). These results suggest that, in answer to the first research question posited in this study, businesspeople with higher entrepreneurial orientation do report greater possession of distinctive marketing competencies.

\section{Entrepreneurial Orientation and Organizational Perfor- mance}

The overall nature of the relationship between EO and organizational performance was also initially examined using multivariate analysis of variance (MANOVA). The test statistic (Wilks' criterion MANOVA $\mathrm{F}=17.15 ; \mathrm{p} \leq .001)$ indicates that $\mathrm{EO}$ and organizational performance are significantly related. The differences in organizational performance among the three EO groups on each of the seven items (as well as on each group's average performance score) were then individually assessed using a series of univariate ANOVAs. Where significant differences were found, Tukey-Kramer pairwise comparison tests were again employed. Results of the univariate ANOVAs and pairwise comparisons can be found in Table 2 .

As the results in Table 2 indicate, the ANOVA Fvalue is significant for all seven performance items respondents were asked to evaluate. The overall pattern of results is strong with the high EO group means significantly greater than both the medium and low EO group means on all seven performance dimensions. The medium EO group means are also significantly greater than the low EO group means on all measures. An ANOVA based on each group's average performance score also proved significant and produced the same pattern of results when Tukey-Kramer pairwise comparisons were computed. Overall, these findings suggest that, in response to research question two, businesspeople with higher degrees of entrepreneurial orientation do report more favorable organizational performance.

\section{Conclusions}

This article reviewed definitions of entrepreneurship that have been advanced in the literature, prior research linking EO with marketing competence and organizational performance and proposed a new, six-item scale for measuring EO. Results indicate the new EO scale demonstrated an acceptable level of reliability and holds potential. Multivariate and univariate analyses indicate that $\mathrm{EO}$ is related to both distinctive marketing competence and organizational performance.

A closer examination of the results highlights a consistent pattern. Specifically, respondents with higher EO levels report that their businesses both possess a wide variety of distinctive marketing competencies and 
TABLE 1

Results of Analysis of Variance:

Entrepreneurial Orientation Levels and Distinctive Marketing Competencies

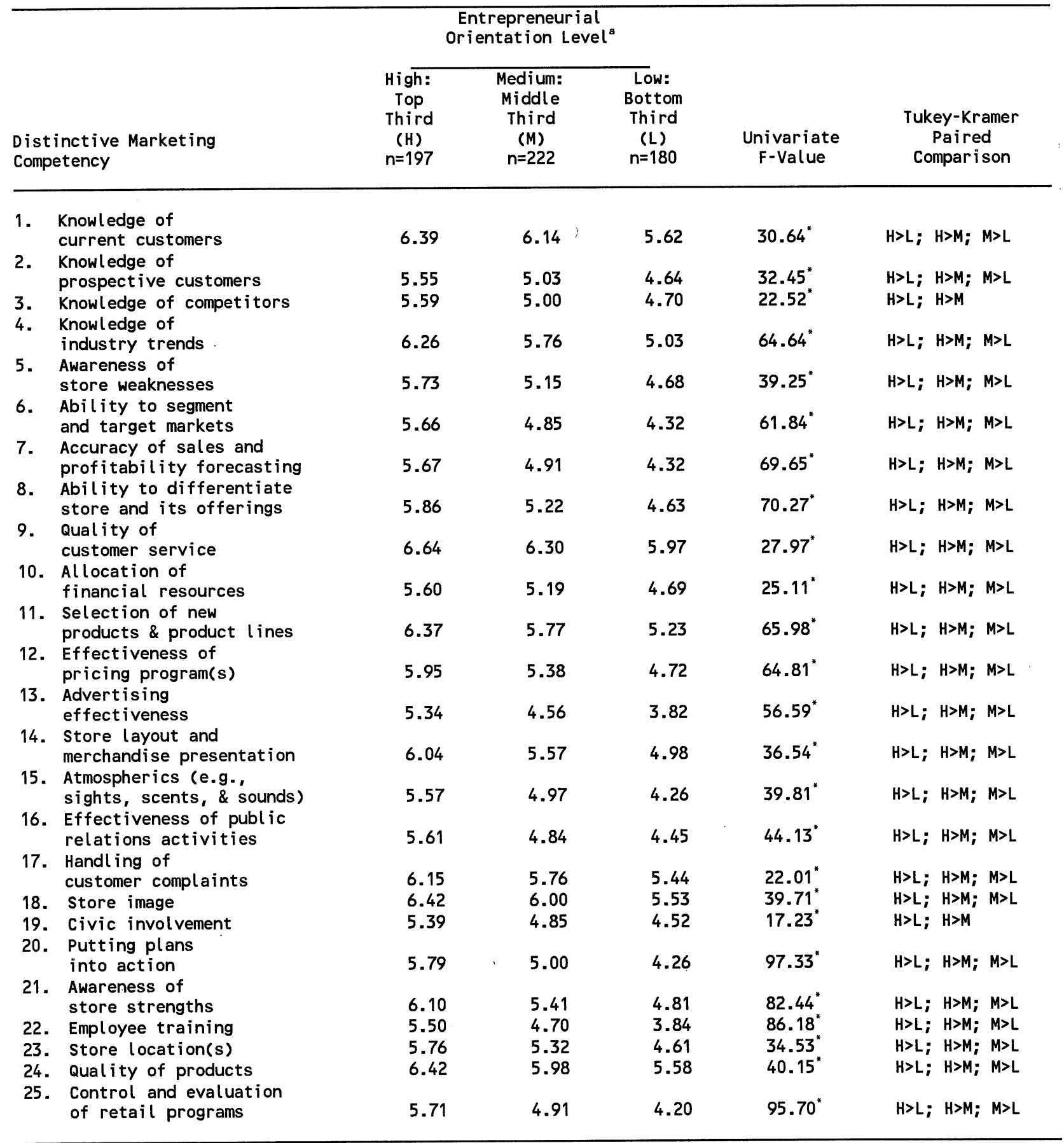

a Responses on six entrepreneurial dimensions were assessed using 7-point

Likert-type scales. Given the comparative nature of these scales, respondents were classified into three approximately equal distributions -- hereafter referred to as the High, Medium, and Low entrepreneurial orientation groups. The summed total ranges for each group are: High (35-42); Medium (30-34); and Low (629).

$* \quad p<.001$ 


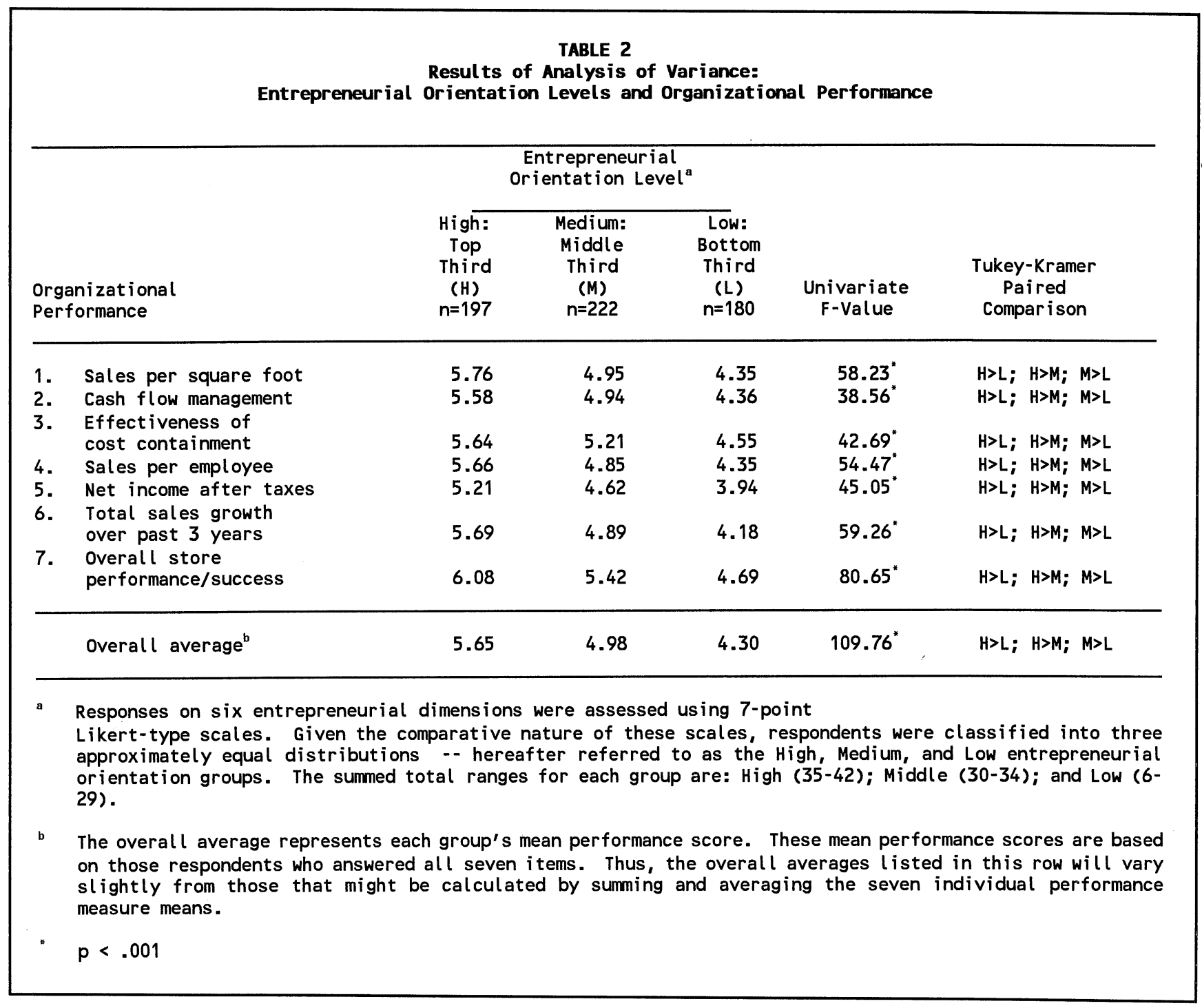

perform better. One possible explanation for the strength of the relationship found to exist between EO and marketing competence may be that, at a fundamental level, "...the interface between marketing and entrepreneurship is extensive" (Hills and LaForge 1992, p. 167). EO has been defined in this study as comprising six dimensions: (1) propensity to take risks; (2) tendency to engage in strategic planning activities; (3) ability to identify customer needs and wants; (4) level of innovation; (5) ability to persevere in making your vision of the business a reality; and (6) ability to identify new opportunities. Contemporary definitions of marketing also place a strong emphasis on need and want identification, planning in process terms, and perseverance as it relates to implementation. For example, one definition states that "Marketing is the process of planning and executing the conception, pricing, promotion, and distribution of ideas, goods, and services to create exchanges that satisfy individual and organizational objectives" (Ferrell and Lucas, 1987, p. 15).

The positive relationship found to exist between EO and organizational performance indicates that successful entrepreneurs possess a wide variety of managerial attributes and skills. While they may have a higher propensity for risk, their ability to identify customer needs and tendency to engage in strategic planning activities, for example, indicate that they are very analytic in their approach to decision making and resource allocation.

\section{Suggestions for Future Research}

The independent apparel retailers who participated in this study represent only one context within which the EO-distinctive marketing competence and EO-organizational performance relationships might be examined. It is possible that marketing competencies are more 
important in such a highly competitive arena and differences among EO groups could be less striking in other sectors. Independent wholesalers and privatelyowned manufacturers, in addition to other types of independent retailers (e.g., electronics stores, toy stores) should be studied in future research.

This study did not explicitly control for whether the business was a startup or had been functioning for several years. Wortman (1987) suggests studying ventures that have survived for a stated period of time so that success or failure factors can be determined. However, indications also exist that businesses go through stages of development (Steinmetz, 1969), as do entrepreneurs themselves (Bird, 1989), and those effects should be taken into account when designing a study that compares businesses based on their longevity.

Another potentially important contingency variable is the general economic climate within which the business is currently operating. It is plausible that the local economy might affect respondents' competency and performance evaluations. Since many of the independent businesses surveyed in the present study were situated in the southeast and southcentral sections of the U.S., the prevailing economic conditions at the time might have played a role, not necessarily in the direction of the response, but possibly in the magnitude of perceived differences.

Although there is support for the acceptability and usefulness of subjective, self-report measures of organizational performance, future research utilizing objective measures is needed. Respondents, especially independent businesspeople who manage privately-owned firms, are often reluctant to share objective performance information. Scholars must confront the challenge to effectively communicate to respondents that individual responses will never be identified and performance information will always be presented in summary fashion.

Future research should also explore more comprehensively the educational backgrounds of respondents. The results reported here were consistent with Cooper and Dunkelberg's (1987) finding that the majority of entrepreneurs had education beyond high school and were, in general, better educated than the population at large. The present study did not explore respondents' majors (for those that indicated they had attended or completed college) or number and type of business courses taken. Have high EO group respondents, for example, completed more marketing courses than low EO group respondents? Conversely, have high EO group respondents developed their marketing competencies through continuing education programs, intuition, or experience? This information would enhance our understanding of how competencies are fostered and developed.

The authors wish to thank Roberto Solano-Mendez of Texas A\&M University for his assistance. The financial support provided for this project by Texas A\&M University's Center for Entrepreneurship and New Venture Management, Center for Retailing Studies, and Office of University Research is also gratefully acknowledged.

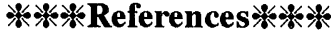

1. Begley, Thomas M., and Boyd, David P., "Psychological Characteristics Associated with Performance in Entrepreneurial Firms and Smaller Businesses," Journal of Business Venturing, Vol. 2, pp. 79-93, 1987.

2. Berman, Barry, and Evans, Joel R., Retail Management: A Strategic Approach, Macmillan Publishing Company, New York. 1989.

3. Bird, Barbara J., Entrepreneurial Behavior, Scott, Foresman and Company, Glenview, Illinois, 1989.

4. Carland, James, Hoy, Frank, Boulton, William, and Carland, JoAnn C., "Differentiating Entrepreneurs From Small Business Owners: A Conceptualization," Academy of Management Review, Vol. 9, pp. 354-359, 1984.

5. Carland, James W., Hoy, Frank, and Carland, JoAnn C., "'Who is an Entrepreneur?' Is a Question Worth Asking," American Journal of Small Business, Vol. 12, pp. 33-39 1984.

6. Churchill, Gilbert A., Jr., and Peter, J. Paul, "Research Design Effects on the Reliability of Rating Scales: A Meta-Analysis," Journal of Marketing Research, Vol. 21, pp. 360-375, 1984.

7. Churchill, Neil C., and Lewis, Virginia, "Entrepreneurial Research Directions and Methods," in D. L. Sexton and R. W. Smilor, eds., The Art and Science of Entrepreneurship, Ballinger Publishing Company, Cambridge, Massachusetts, pp.333-365, 1986.

8. Conant, Jeffrey S., Mokwa, Michael P., and Varadarajan, P. Rajan, "Strategic Types, Distinctive Marketing Competencies and Organizational Performance: A Multiple Measures-Based Study," Strategic Management Journal, Vol. 11, pp. 365-383, 1990.

9. Cooper, Arnold C., and Dunkelberg, William C., "Entrepreneurship and Paths to Business Ownership," Strategic Management Journal, Vol. 7, pp. 5368, 1986.

10. Cooper, Arnold C., and Dunkelberg, William C., "Entrepreneurial Research: Old Questions, New Answers and Methodological Issues," American Journal of Small Business, Vol. 11, pp. 11-23, 1987.

11. Covin, J.G., and Slevin, D.P., "Strategic Management of Small Firms in Hostile and Benign Environments," Strategic Management Journal, Vol. 10, pp. 75-87, 1989.

12. Cunningham, J. Barton, and Lischeron, Joe, "Defin- 
ing Entrepreneurship," Journal of Small Business Management, Vol. 29, pp. 45-61, 1991.

13. Davis, Duane, Morris, Michael, and Allen, Jeff, "Perceived Environmental Turbulence and Its Effect on Selected Entrepreneurship, Marketing and Organizational Characteristics in Industrial Firms," Journal of the Academy of Marketing Science, Vol. 19, pp. 43-51, 1991.

14. Dess, Gregory G., and Robinson, Richard B., Jr., "Measuring Organizational Performance in the Absence of Objective Measures: The Case of the Privately-held Firm and Conglomerate Business Unit," Strategic Management Journal, Vol. 5, pp. 265273, 1984.

15. Dillman, Don A., Mail and Telephone Surveys: The Total Design Method, John Wiley and Sons, New York. 1978.

16. Ferrell, O. C. and Lucas, G. H., Jr., "An Evaluation of Progress in the Development of a Definition of Marketing," Journal of the Academy of Marketing Science, Vol. 15, pp. 12-23, 1987.

17. Fiorito, Susan S., and LaForge, Raymond W., "A Marketing Strategy Analysis of Small Retailers," American Journal of Small Business, Vol. 11, pp. 717, 1986.

18. Gartner, William B., "A Conceptual Framework for Describing the Phenomenon of New Venture Creation," Academy of Management Review, Vol. 10, pp. 696-706, 1985.

19. Gartner, William B., "Who is the Entrepreneur?' Is the Wrong Question," American Journal of Small Business, Vol. 12, pp. 11-32, 1988.

20. Hills, G. E. and LaForge, R. W., "Marketing and Entrepreneurship: The State of the Art," in D. L. Sexton, J. D Kasarda, eds., The State of the Art of Entrepreneurship, PWS-Kent Publishing, Boston, pp. 164-190, 1992.

21. Hitt, Michael A., and Ireland, R.D., "Corporate Distinctive Competence, Strategy, Industry, and Performance," Strategic Management Journal, Vol. 6, pp. 273-293, 1985.

22. Jones, W. David, "Characteristics of Planning in Small Firms," Journal of Small Business Management, Vol. 20, pp. 15-19, 1982.

23. Kalleberg, Arne L., "Entrepreneurship in the 1980s: A Study of Small Business in Indiana," in Gary Libecap, ed., Advances in the Study of Entrepreneurship, Innovation, and Economic Growth, Vol. 1., JAI Press, Greenwich, Connecticut, pp. 157-189, 1986.

24. Keats, Barbara W. and Bracker, Jeffrey S., "Toward a Theory of Small Firm Performance: A Conceptual Model," American Journal of Small Business, Vol. 12, pp. 41-58, 1988.

25. Kuratko, Donald F., and Hodgetts, Richard M., Entrepreneurship A Contemporary Approach, The Dryden Press, Fort Worth, Texas, 1992.

26. Long, Wayne, "The Meaning of Entrepreneurship,"
American Journal of Small Business, Vol. 8, pp. 4759, 1983.

27. Low, Murray B., and MacMillan, Ian C., "Entrepreneurship: Past Research and Future Challenges," Journal of Management, Vol. 14, pp. 139-161, 1988.

28. Main, Jeremy, "A Golden Age For Entrepreneurs," Fortune, Vol. 121, pp. 120-125, 1990.

29. Mason, J. Barry, and Mayer, Morris L., Modern Retailing: Theory and Practice, Business Publications, Inc., Plano, Texas, 1987.

30. McClelland, David C., The Achieving Society, D. Van Nostrand, Princeton, New Jersey, 1965.

31. Meziou, Fekri, "Areas of Strength and Weakness in the Adoption of the Marketing Concept by Small Manufacturing Firms," Journal of Small Business Management, Vol. 29, pp. 72-78, 1991.

32. Miles, Morgan P., and Arnold, Danny R., "The Relationship Between Marketing Orientation and Entrepreneurial Orientation," Entrepreneurship Theory and Practice, Vol. 15, pp. 49-65, 1991.

33. Morris, Michael H., and Paul, Gordon W., "The Relationship Between Entrepreneurship and Marketing in Established Firms," Journal of Business Venturing, Vol. 2, pp. 247-259, 1987.

34. Nicholson, Richard, "Managing Emerging Business," in Clifford M. Baumback and Joseph R. Mancuso, eds., Entrepreneurship and Venture Management, Clifford M. Baumback and Joseph R. Mancuso, eds., Prentice Hall Inc., Englewood Cliffs, New Jersey, pp. 277-282, 1986.

35. Nunnally, J.C., Psychometric Theory, McGraw-Hill, New York, 1978.

36. Robinson, Richard B., Jr., and Pearce, John A. II, "Research Thrusts in Small Firm Strategic Planning," Academy of Management Review, Vol. 9, pp. 128-137, 1984.

37. Robinson, Richard B., Jr., Logan, John E., and Salem, Moragea Y., "Strategic Versus Operational Planning in Small Firms," American Journal of Small Business, Vol. 10, pp. 7-16, 1986.

38. Schumpeter, J. A., The Theory of Economic Development, Harvard University Press, Cambridge, Massachusetts, 1934.

39. Snow, Charles C. and Hrebiniak, Lawrence G., "Strategy, Distinctive Competence, and Organizational Performance," Administrative Science Quarterly, Vol. 25, pp. 317-336, 1980.

40. Steinmetz, Lawrence L., "Critical Stages of Small Business Growth," Business Horizons, Vol. 12, pp. 29-36, 1969.

41. Van de Ven, Andrew H., Hudson, Roger, and Schroeder, Dean, M., "Designing New Business Startups: Entrepreneurial, Organizational, and Ecological Considerations," Journal of Management, Vol. 10, pp. 87-107, 1984.

42. Venkatraman, N., and Ramanujam, Vasudevan, "Measurement of Business Economic Performance: An Examination of Method Convergence," Journal 
of Management, Vol. 13, pp. 109-122, 1987.

43. Vesper, K. H., New Venture Strategies, Prentice-Hall, Englewood Cliffs, New Jersey, 1980.

44. Wortman, Max S., Jr., "Entrepreneurship: An Integrating Typology and Evaluation of the Empirical Research in the Field," Journal of Management, Vol. 13, pp. 259-279, 1987. 